\title{
When should we assess tricuspid regurgitation severity? Preoperatively, while the patient is awake
}

Juan A. Crestanello, MD

From the Department of Cardiovascular Surgery, Mayo Clinic, Rochester, Minn.

Disclosures: Author has nothing to disclose with regard to commercial support

Received for publication April 24, 2018; accepted for publication April 25, 2018; available ahead of print June 5, 2018

Address for reprints: Juan A. Crestanello, MD, Department of Cardiovascular Surgery, Mayo Clinic, 200 First St SW, Rochester, MN 55905 (E-mail: crestanello.juan@mayo.edu).

J Thorac Cardiovasc Surg 2018;156:1512-3

$0022-5223 / \$ 36.00$

Copyright (c) 2018 by The American Association for Thoracic Surgery

https://doi.org/10.1016/j.jtcvs.2018.04.097

The current understanding of tricuspid valve function in health and disease is incomplete. The tricuspid valve is a complex structure, and its competency depends on the precise interaction of the valve leaflets, the annulus, the subvalvular apparatus, the interventricular septum, and the right ventricle (Figure 1).,

The accurate assessment of tricuspid valve morphology and function includes the assessment not only of the tricuspid valve but also of the right and left ventricles. It should involve multiple modalities, which include 2- and 3-dimensional echocardiography, cardiac magnetic resonance imaging, computed tomography, and invasive hemodynamic measurements. ${ }^{1,2}$

Functional tricuspid regurgitation secondary to left-sided heart disease is a topic of passionate debate among the experts, particularly in term of its prognostic implications and the need for and type of surgical treatment. ${ }^{2-7}$ Although consensus appears to exist regarding the need to address severe tricuspid regurgitation associated with left-sided heart disease, there is still substantial controversy as to whether moderate tricuspid regurgitation or lesser degrees of regurgitation with a dilated tricuspid annulus need to be addressed. ${ }^{2-7}$ The results of the ongoing Cardiothoracic Surgery Trials Network trial (Evaluating the Benefit of Concurrent Tricuspid Valve Repair during Mitral Surgery, ClinicalTrials.gov identifier NCT02675244) will likely help to clarify these issues.

In this issue of the Journal, Jazwiec and colleagues ${ }^{8}$ report their study of the effect of general anesthesia on the geometry and function of the tricuspid valve in sheep, as measured with sonomicrometry crystals, echocardiography, and invasive hemodynamic measurements. In these experiments, sheep were anesthetized and implanted with instrumentation. After 1 week of recovery, the tricuspid valve was studied while the sheep were awake and then studied again with the sheep under general anesthesia. Jazwiec and colleagues ${ }^{8}$ found that general anesthesia (1) was not associated with any substantial changes in systemic or pulmonary hemodynamics, (2) decreased

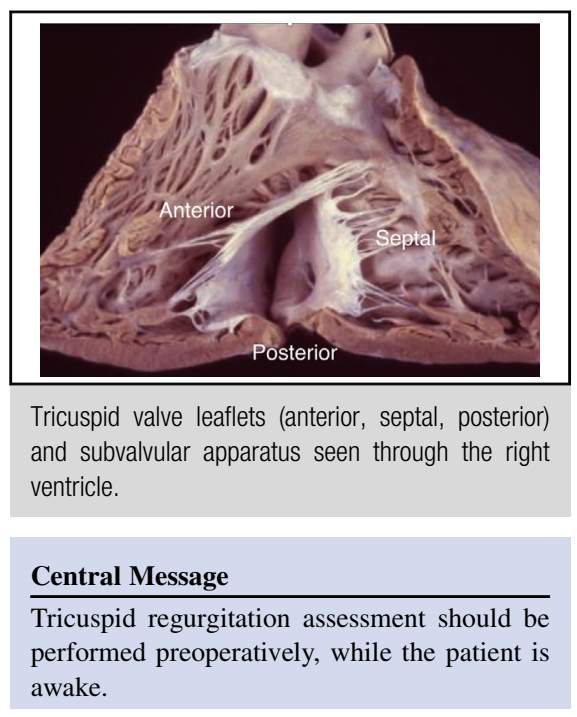

See Article page 1503 .

systolic contraction of the tricuspid valve annulus secondary to decreased contraction of the septal portion of the annulus, (3) did not change the geometry of the right ventricle and subvalvular apparatus, (4) depressed the contractility of the free wall of the right ventricle, and (5) increased the severity of tricuspid regurgitation. Because there is no change in the geometry of the subvalvular apparatus, tricuspid regurgitation is likely related to decreased annular contraction during systole. The effects of cardiopulmonary bypass were not studied by Jazwiec and colleagues. ${ }^{8}$ Nonetheless, it is important to highlight that cardiopulmonary bypass and aortic crossclamping would likely exacerbate tricuspid regurgitation even further and perhaps more profoundly than general anesthesia alone. Cardiopulmonary bypass may adversely affect the severity of tricuspid regurgitation through several mechanisms, including (1) increased pulmonary vascular resistances and right ventricular afterload; (2) right ventricular dysfunction secondary to ischemia reperfusion, stunning, air embolization into the right coronary artery, or inadequate myocardial protection; and (3) abnormal interventricular septal motion. The importance of the free wall of the right ventricle and the interventricular septum for right ventricular function has been highlighted by Buckberg and others. ${ }^{9-11}$ Displacement of the free wall of the right ventricle and interventricular septum not only affect right ventricular 


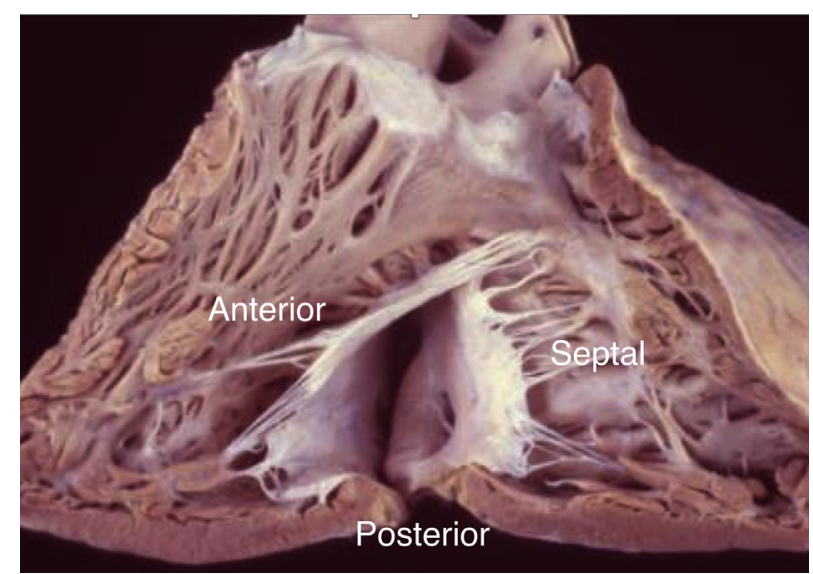

FIGURE 1. Tricuspid valve leaflets (anterior, septal, and posterior) and subvalvular apparatus seen from the right ventricle. Notice the attachments of the chordae tendineae to the ventricular walls.

function but also produce tricuspid leaflet tethering, resulting in tricuspid regurgitation. In addition, the abnormal septal function likely impairs tricuspid annular contraction during systole even further. These changes are usually temporary and likely to reverse with reperfusion and increased perfusion pressures.

Although Jazwiec and colleagues ${ }^{8}$ are to be congratulated for their rigorous performance of complex and technically demanding experiments, the reader should be aware that the changes described were of marginal statistical significance and were limited to sheep, with no corroboration in human subjects. Recognizing these limitations, it is legitimate to ask what the clinical implications of these findings are, and how general anesthesia may affect our ability to assess tricuspid regurgitation severity. It appears that general anesthesia as well as cardiopulmonary bypass may lead to an overestimation of tricuspid regurgitation severity. If confirmed, these finding will affect our judgment of the intraoperative assessment of tricuspid regurgitation severity before and after cardiopulmonary bypass. These results should give pause to those who have made clinical decisions on the basis of the intraoperative echocardiographic data alone. The decision to address tricuspid regurgitation should be based on multimodal preoperative assessment performed while the patient is awake.

\section{References}

1. Huttin O, Voilliot D, Mandry D, Venner C, Juillière Y, Selton-Suty C. All you need to know about the tricuspid valve: tricuspid valve imaging and tricuspid regurgitation analysis. Arch Cardiovasc Dis. 2016;109:67-80.

2. Dreyfus GD, Martin RP, Chan KM, Dulguerov F, Alexandrescu C. Functional tricuspid regurgitation: a need to revise our understanding. J Am Coll Cardiol. 2015;65:2331-6.

3. Shinn SH, Schaff HV. Evidence-based surgical management of acquired tricuspid valve disease. Nat Rev Cardiol. 2013;10:190-203.

4. Chikwe J, Itagaki S, Anyanwu A, Adams DH. Impact of concomitant tricuspid annuloplasty on tricuspid regurgitation, right ventricular function, and pulmonary artery hypertension after repair of mitral valve prolapse. J Am Coll Cardiol. 2015;65:1931-8.

5. Yilmaz O, Suri RM, Dearani JA, Sundt TM III, Daly RC, Burkhart HM, et al. Functional tricuspid regurgitation at the time of mitral valve repair for degenerative leaflet prolapse: the case for a selective approach. J Thorac Cardiovasc Surg. 2011;142:608-13.

6. Dion RA. Is the air in Toronto, Rochester, and Cleveland different from that in London, Monaco, Leiden, Genk, Milan, and New York? J Thorac Cardiovasc Surg. 2015;150:1040-3.

7. David TE, David CM, Manhiolt C. When is tricuspid valve annuloplasty necessary during mitral valve surgery? J Thorac Cardiovasc Surg. 2015;150:1043-4.

8. Jazwiec T, Malinowski M, Proudfoot AG, Eberhart L, Langholz D, Schubert H, et al. Tricuspid valvular dynamics and 3-dimensional geometry in awake and anesthetized sheep. J Thorac Cardiovasc Surg. 2018;156:1503-11.

9. Nguyen T, Cao L, Movahed A. Altered right ventricular contractile pattern after cardiac surgery: monitoring of septal function is essential. Echocardiography. 2014;31:1159-65.

10. Buckberg G, Hoffman JI. Right ventricular architecture responsible for mechanical performance: unifying role of ventricular septum. J Thorac Cardiovasc Surg. 2014;148:3166-71. e1-4.

11. Buckberg GD, RESTORE Group. The ventricular septum: the lion of right ventricular function, and its impact on right ventricular restoration. Eur J Cardiothorac Surg. 2006;29(Suppl 1):S272-8. 